\title{
Competência em Informação na Educação Profissional: avaliação de estudantes de um curso técnico integrado ao Ensino Médio
}

\author{
Information Literacy in Vocational Education and \\ Training: assessment of students from a technical course \\ integrated to High School
}

\author{
Carlos Robson Souza da Silva a,* (iD \\ Thiciane Mary Carvalho Teixeira a (D)
}

\begin{abstract}
RESUMO: A avaliação da competência em informação é um instrumento essencial e se utiliza de padrões, modelos e indicadores para ser realizada com sucesso. No contexto da Educação Profissional e Tecnológica, autores como Santos (2017) e Oliveira e Silva (2018) apontam a validade dos Padrões de Competência em Informação da ACRL (2000) para a avaliação da competência em informação de futuros trabalhadores. Neste sentido, o presente trabalho tem como objetivo avaliar a aquisição de Competência em Informação de estudantes concludentes de um curso técnico integrado ao Ensino Médio. Utilizou um questionário de múltipla escolha orientado pela Matriz Conceitual de Oliveira e Silva (2020) aplicado a estudantes concludentes de um curso técnico integrado ao Ensino Médio. Identificou-se que os estudantes acreditam que a informação molda aspectos do cotidiano, do trabalho e da educação, e que possuem habilidades específicas para a identificação das necessidades de informação, para o acesso, a avaliação e o uso da informação, e para a compreensão das questões que cercam a informação. Concluise que o coletivo de estudantes possui habilidades informacionais desenvolvidas, entretanto que precisam de uma formação mais adequada para entender como a informação é produzida e identificar informações enviesadas (como fake news). Considera-se também a necessidade de se criar indicadores para a Educação Profissional e Tecnológica no Brasil alinhados aos avanços nos estudos sobre Competência em Informação.
\end{abstract}

Palavras-chave: Competência em Informação; Educação Profissional e Tecnológica; Avaliação da Competência em Informação.

ABSTRACT: The information literacy assessment is an essential instrument and uses standards, models and indicators to be successfully done. In Vocational Education and Training, authors like Santos (2017) and Oliveira and Silva (2018) affirms the validity of ACRL's Information Literacy Competency Standards in the assessment of the future workers' information literacy. In this context, this work aims assess the acquisition of Information Literacy of students graduating a technical course integrated to high school. It used a questionnaire with multiple choice questions oriented by the Conceptual Framework Oliveira e Silva (2020), applied to the group intended. It identified that the students believe in the fact that information is present in all aspects of the live and that them have specific abilities to identify their information needs, access, evaluate and use information, and comprehend the issues which surround information. It concludes that the students have good information skills, but that they need to access an education that introduce them to understand how information is produced and identify fake news. It also considers the need to create indicators which must be specifically applied to Vocational Education and Training in Brazil and in according to the Information Literacy studies.

Keywords: Information Literacy; Vocational Education and Training; Information Literacy Assessment.

a Programa de Pós-Graduação em Ciência da Informação, Universidade Federal do Ceará, Fortaleza, CE, Brasil.

*Correspondência para/Correspondence to: Carlos R. Souza da Silva. E-mail: crobsonss@gmail.com. Endereço: Alameda José Quintino, s/n, Prado - Cedro, CE, Brasil, CEP 63400-000.

Recebido em/Received: 14/12/2020; Aprovado em/Approved: 04/04/2021.

Artigo publicado em acesso aberto sob licença CC BY 4.0 Internacional @() 


\section{INTRODUÇÃO}

As discussões sobre a necessidade de desenvolvimento de habilidades informacionais, chamadas conjuntamente de Competência em Informação, remontam ao fim do Século XX, quando as novas tecnologias da informação e da comunicação se estabeleceram como novo paradigma industrial, moldando serviços e produtos e a própria sociedade que passou a se chamar Sociedade da Informação.

Desde então começou-se a discutir métodos e práticas que permitissem a introdução da Competência em Informação no currículo escolar e universitário de modo a que os estudantes pudessem aprender a lidar com a informação e os produtos, serviços, tecnologias e fenômenos sociais por ela moldados de maneira crítica e ativa.

Como meio de auxiliar no processo educativo, mas principalmente no processo de avaliação de Competência em Informação dos estudantes, criou-se inúmeros modelos e padrões, como os Padrões de Competência em Informação da americana Associação de Bibliotecas Universitárias e de Pesquisa (ACRL 2000), que afirmava que os estudantes, para se tornarem competentes em informação, deveriam saber identificar as necessidades de informação, acessar as informações de que precisam, avaliá-las, usá-las e compreender as questões sociais, políticas e econômicas que cercam o seu acesso e uso.

Iniciativas parecidas podem ser vistas em outros modelos, como o Information Power da Associação Americana de Bibliotecas Escolares (AASL e AECT 1998), os Sete Pilares da Competência em Informação da britânica Sociedade de Bibliotecas Escolares, Nacionais e Universitárias (SCONUL 2011) e os "Padrões de Competência em Informação" do Conselho Australiano de Bibliotecas Universitárias e do Instituto Australiano e Neozelandês pela Competência em Informação (CAUL e ANZIL 2004).

Tais modelos e padrões passaram, entretanto, por um processo de revisão, principalmente os Padrões da ACRL, substituídos desde 2016, pelo Framework sobre Competência em Informação (ACRL 2016) e o Information Power da AASL (2009) substituídos recentemente pelos Padrões de Aprendizagem para o Século 21, trazendo uma proposta mais qualitativa baseadas em conceitos para a avaliação da Competência em Informação.

Acredita-se aqui, porém que, os modelos anteriores ainda possuem relevância no processo de avaliação da competência em informação, principalmente no Brasil, onde o ensino voltado para o acesso, a avaliação e o uso da informação não é institucionalizado e não está evidente nos documentos oficiais sobre Educação do país, sendo utilizados como base da criação de indicadores de avaliação da competência em informação em ambientes educacionais antes não assistidos, como é o caso da Educação Profissional e Tecnológica.

Tendo esse pano de fundo, este trabalho resultou-se de uma pesquisa de campo que foi aplicada em um campus do Instituto Federal de Educação, Ciência e Tecnologia do Ceará (IFCE), tendo como principal questionamento: que habilidades informacionais são 
evidenciadas por discentes concludentes de um curso técnico de nível médio integrado ao Ensino Médio?

A partir desse questionamento, tem-se aqui como objetivo avaliar a aquisição de competência em informação desses discentes tendo como modelo orientador os Padrões de Competência em Informação da ACRL (2000) e uma Matriz Conceitual voltada para a Competência em Informação na Educação Profissional desenvolvida por Oliveira e Silva (2018).

\section{AVALIAÇÃO DA COMPETÊNCIA EM INFORMAÇÃO: MODELOS E EXPERIÊNCIAS}

A Competência em Informação faz parte de uma série de discussões dentro da Biblioteconomia e da Ciência da Informação que surgem no momento em que a informação e suas tecnologias reformam a maneira de se compreender o mundo, de se transformá-lo e de se adaptar a ele.

Ela pode ser entendida como

$$
\begin{aligned}
& \text { o processo contínuo de internalização de fundamentos conceituais, } \\
& \text { atitudinais e de habilidades necessário à compreensão e interação } \\
& \text { permanente com o universo informacional e sua dinâmica de modo a } \\
& \text { proporcionar um aprendizado ao longo da vida (Dudziak 2003, p. } 28 \text {, } \\
& \text { grifo da autora). }
\end{aligned}
$$

A Competência em Informação é, desta forma, intrínseca aos indivíduos, principalmente aqueles inseridos nas atuais dinâmicas sócio-informacionais. Apesar disso, o seu desenvolvimento permite o preparo para que se possa realizar buscas por informação com eficiência, a avaliar a informação com criticidade e a usar a informação, seus produtos, serviços e tecnologias de maneira ética.

Por possuir a necessidade de ser desenvolvida ao longo da vida, a Competência em Informação apresenta a importância de pensá-la a partir de todas as dimensões e experiências individuais e coletivas (como no trabalho, nos momentos de lazer e no cotidiano como um todo), mas principalmente dentro do contexto da educação formal, devendo ser incluída em todas as etapas do processo formativo (desde o Ensino Infantil aos altos níveis de estudo de Pós-Graduação), mas também em modalidades específicas como é o caso da Educação Profissional.

A relação entre a Competência em Informação e a Educação perpassa todos os processos de ensino e de aprendizagem que esta última se propõe a trazer para os estudantes. Sendo uma competência que transita todas as áreas (pois a própria informação transita todas as dimensões da vida), deve-se repensar um currículo que atenda às necessidades de aprendizagem e, consequentemente, avaliação dos estudantes quanto a sua competência em informação.

Avaliação da Competência em Informação, processo que deve ser contínuo, está intrinsecamente ligada à própria história da Competência em Informação e torna 
possível, através da criação de modelos, padrões e indicadores, facilitar a captura do processo informacional, racionalizá-lo, transformá-lo em processo adaptável de ensino e de aprendizagem e submetê-lo consequentemente à avaliação, traçando assim “[... ] um diagnóstico que fornece indicadores para melhorar a aplicação dos programas e atividades sobre o tema e em muitos casos justifica a necessidade de implantação destes programas". (Santos e Casarin 2014, p. 135).

Os modelos, padrões e indicadores, ora enfocando-se no ensino básico, ora enfocandose no ensino superior, têm como perspectiva apresentar instrumentos ou rotas para avaliar o processo que um sujeito deve seguir para desenvolver de forma eficiente e efetiva suas habilidades informacionais.

Destaca-se aqui os Padrões de Competência em Informação no Ensino Superior da americana Associação de Bibliotecas Universitárias e de Pesquisa (ACRL 2000), que foi por muito tempo um dos principais modelos de Competência em Informação no mundo, influenciando por exemplo o Framework Australiano e Neozelandês de Competência em Informação do Instituto Australiano e Neozelandês de Competência em Informação (Caul e Anzil 2004) e os Padrões de Competência em Informação de Belluzzo e Kerbauy (2004).

Constituído de cinco padrões, vinte e dois indicadores e inúmeros resultados esperados, o modelo da ACRL (2000) indica que um estudante competente em informação deve saber identificar as suas necessidades de informação, acessar a informação, avaliar a informação, usar a informação e compreender as questões que cercam o acesso e uso da informação.

Apesar de inicialmente direcionado ao contexto da Educação Superior tradicional e de recentemente substituído pelo Framework de Competência em Informação no Ensino Superior também da ACRL (2016), o modelo, principalmente no Brasil, também foi utilizado em outros contextos, como é o caso da Educação Profissional e Tecnológica. Autores como Santos (2017) e Oliveira e Silva (2018) recorreram aos Padrões da ACRL (e seus derivados) para criar referenciais conceituais na construção de modelos de Competência em Informação.

Com essa aplicação na Educação Profissional, tanto Santos (2017) quanto Oliveira e Silva (2018), apontam para um entendimento da validade dos Padrões da ACRL (2000) em uma modalidade educacional que tem como proposta de superar a dualidade entre trabalho e educação.

Pensar Competência em Informação no contexto da Educação Profissional é se atentar às peculiaridades da modalidade e também aos seus fundamentos teóricos e práticas educativas. Para se atrelar aos modelos de Educação Profissional mais recentemente adotados, é preciso se pensar uma Competência em Informação também politécnica, integrada, omnilateral e que prepare o profissional habilitado a atuar em um mundo do trabalho cada vez mais informacional. 
De acordo com Santos (2017, p. 102, grifo da autora), no contexto da Educação Profissional, a Competência em Informação

[...] faz com que o discente aplique a informação na prática para a compreensão e intervenção crítica e responsável de fatos, fenômenos e da realidade, resolução de problemas, a tomada de decisões no ambiente escolar e, futuramente, no ambiente de trabalho.

Por possuir essa peculiaridade, modelos e programas têm sido desenvolvidos para que estudantes dessa modalidade também possam adquirir e desenvolver criticamente suas habilidades informacionais, destacando-se aqui a proposta de Oliveira e Silva (2018).

Oliveira e Silva (20188) através de sua Matriz Conceitual (Quadro 1), buscam articular a Competência em Informação à corrente da Educação Profissional e Tecnológica que se estabelece sobre o conceito de politecnia, enquanto "[...] domínio dos fundamentos científicos das diferentes técnicas que caracterizam o processo do trabalho moderno" (Saviani 2003, p. 140 citado por Brasil 2007, p. 17), de omnilateralidade, que tem como “[...] base a integração de todas as dimensões da vida no processo educativo [trabalho, ciência, cultura e tecnologia]" (Brasil 2007) e de Ensino Médio enquanto etapa final da educação básica que, de acordo com a Lei de Diretrizes e Bases da Educação Nacional, deve atender à formação geral do educando, podendo também habilitar para profissões técnicas (Brasil 1996 citado por Brasil 2007).

Essa nova forma de entender a Educação Profissional, presente principalmente no que é chamado de Educação Profissional Técnica de Nível Médio Integrada ao Ensino Médio (Brasil 2007)', permite que seja realizada a oferta de uma formação integrada, crítica e que englobe todos os aspectos e dimensões da vida dos estudantes e futuros trabalhadores, sem excluir a aquisição de uma habilitação profissional específica e reconhecida.

A Matriz Conceitual para o desenvolvimento de um modelo de Competência em Informação na Educação Profissional de Oliveira e Silva (2018), dessa forma, relaciona conceitos da Educação Profissional e da Competência em Informação de modo a nortear a criação de programas de ensino, metodologias de avaliação e indicadores específicos para a formação integral de trabalhadores, e utiliza como referência o Padrão de Competência em Informação da ACRL (2000).

\footnotetext{
${ }^{1}$ Apesar de que também deve estar presente nas modalidades Formação Inicial e Continuada e Educação Tecnológica de Graduação e Pós-graduação.
} 
Quadro 1. Matriz Conceitual para a Criação de um Modelo de Competência em Informação na Educação Profissional

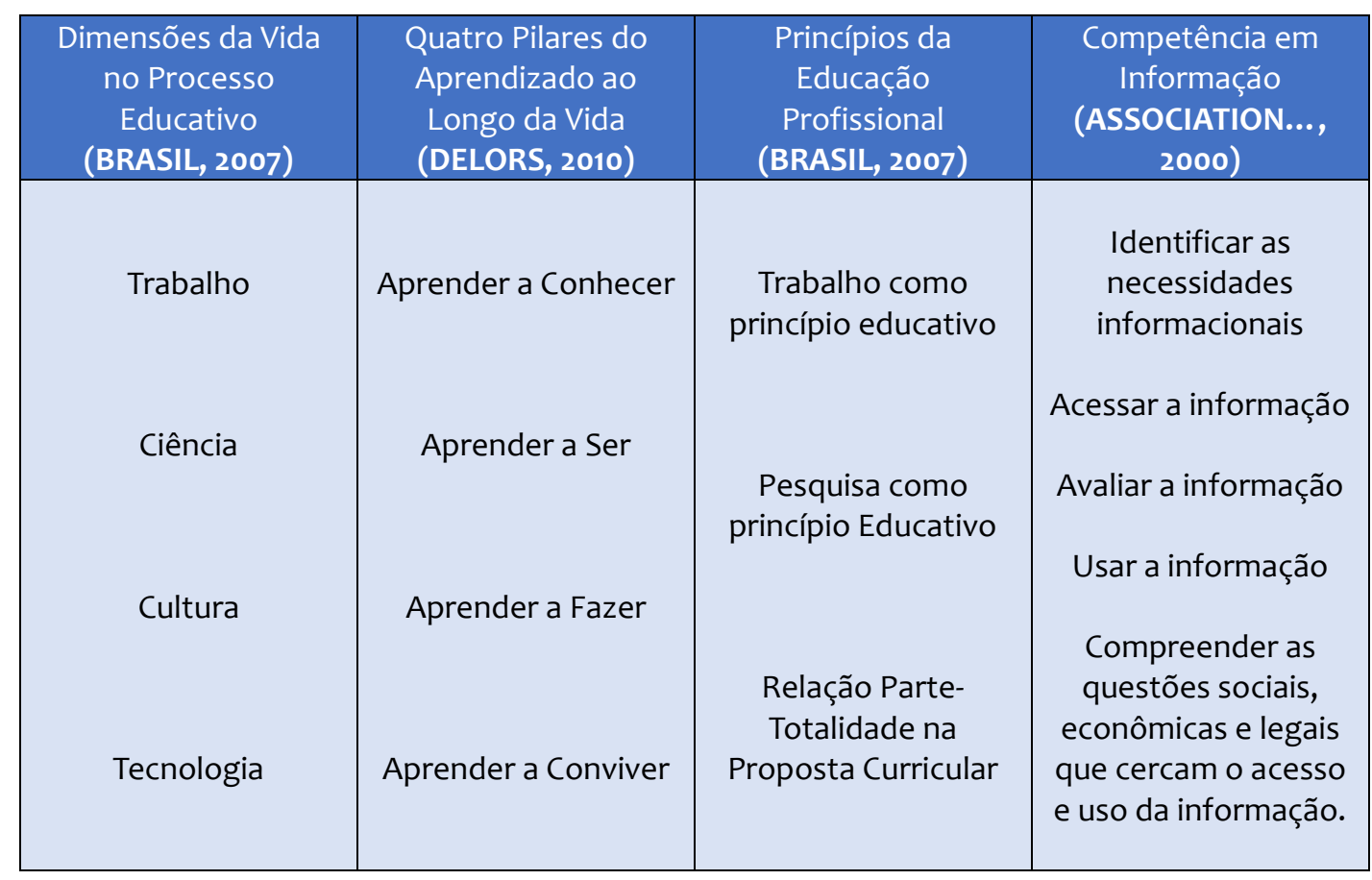

Fonte: adaptado de Oliveira e Silva (2018).

Como é visto na Matriz, as habilidades de Competência em Informação (identificar as necessidades de informação, acessar, avaliar e usar a informação, compreender as questões que cercam a informação), devem estar alinhadas a um processo de aprendizado ao longo da vida (aprender a ser, aprender a conhecer, aprender a conviver e aprender a fazer), que por sua vez devem estar alinhados aos eixos norteadores da Educação Profissional (trabalho como princípio educativo, pesquisa como princípio educativo e relação parte-totalidade na proposta curricular) e da omnilateralidade, ou seja, das dimensões da vida no processo educativo (trabalho, ciência, cultura e tecnologia).

O presente artigo enfocou em trazer questionamentos sobre o processo de desenvolvimento de Competência em Informação de estudantes de um curso técnico de nível médio integrado ao Ensino Médio, utilizando-se principalmente dos Padrões de Competência em Informação da ACRL (2000), entendendo que, apesar de recentemente substituída, ainda seja relevante na criação de instrumentos de coleta de dados para os estudos da área.

\section{PROCEDIMENTOS METODOLÓGICOS}

Este trabalho trata-se de uma pesquisa do tipo exploratória tendo como amostra o Curso Técnico em Eletrotécnica integrado ao Ensino Médio ofertado pelo Instituto Federal de Educação, Ciência e Tecnologia do Ceará (IFCE), campus Cedro.

O presente artigo teve como foco a aplicação e análise de um Questionário destinado aos Discentes do Curso Técnico em Eletrotécnica integrado ao Ensino Médio. 
Nesse sentido, criou-se um questionário fechado de múltipla escolha, baseado no documento "Information Literacy Competency Standards for Higher Education", aqui chamado de Padrões de Competência em Informação da Association of College and Research Libraries (ACRL, 2000), identificado na Matriz Conceitual para a Criação de Modelos de Competência em Informação na Educação Profissional de Oliveira e Silva (2018).

Como o modelo de Competência em Informação da ACRL (2000) é constituído de cinco padrões, possuindo cada padrão uma série de indicadores de performance e cada indicador de performance, resultados esperados, o questionário foi construído da seguinte forma: os Padrões foram transformados em Categorias de Análise, os indicadores de performance transformados em perguntas de múltipla escolha e os resultados esperados transformados nas opções das perguntas de múltipla escolha (ver Quadro 2).

Quadro 2. Comparativo entre os Padrões da ACRL (2000) e o Questionário aos discentes.

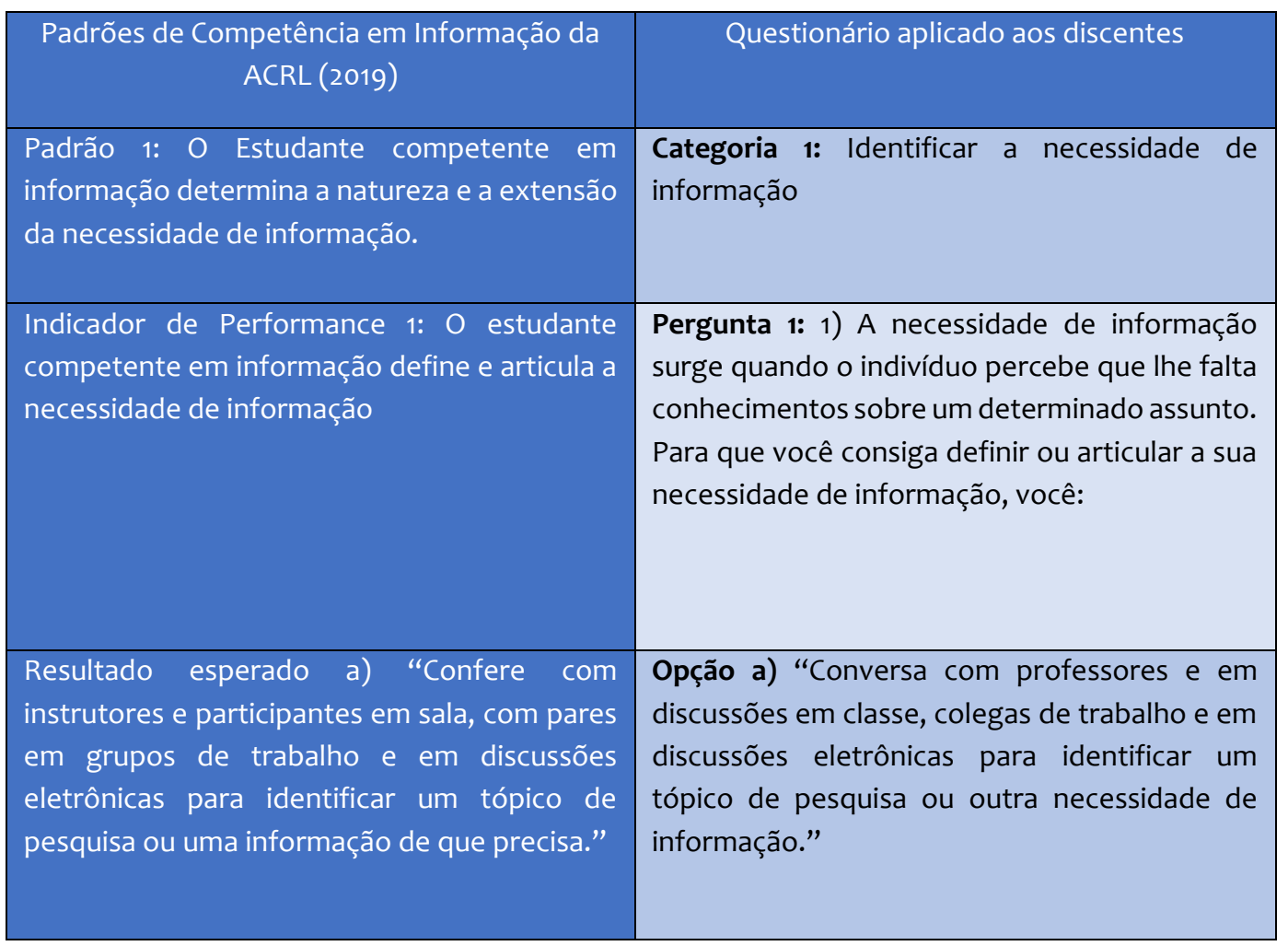

Fonte: os autores (2019).

A proposta desse primeiro momento do questionário voltado aos alunos foi mapear, de acordo com ACRL (2000), suas habilidades informacionais, identificar os fatores de impacto mais positivos e destacar as dificuldades demonstradas ou as práticas preferidas pelos alunos de maneira coletiva, por meio da seleção ou omissão de opções ao longo do questionário. Além disso, acrescentou-se a categoria Informação, Trabalho e Educação, constituído de duas questões fechadas, baseadas na escala Likert. $\mathrm{O}$ quadro 3 abaixo sistematiza as categorias de análise do questionário relacionado aos alunos: 
Quadro 3. Categorias de Análise dos Questionários aos Discentes

\begin{tabular}{|l|l|}
\hline Categoria 1 & Identificar as necessidades de informação \\
\hline Categoria 2 & Acessar a informação \\
\hline Categoria 3 & Avaliar a informação \\
\hline Categoria 4 & Usar a informação \\
\hline Categoria 5 & $\begin{array}{l}\text { Compreender as questões que cercam o uso da } \\
\text { informação }\end{array}$ \\
\hline Categoria 6 & Informação, Trabalho e Educação \\
\hline
\end{tabular}

Fonte: os autores (2019).

A pesquisa foi destinada aos 24 alunos regularmente matriculados no sexto semestre do Curso Técnico em Eletrotécnica integrado ao Ensino Médio (de acordo com os dados oferecidos pela Coordenação de Controle Acadêmico do campus e enviadas à Biblioteca por meio da integração de sistemas), sendo a turma escolhida especificamente por ter passado por todo o processo planejado no Projeto Pedagógico do Curso.

Para manter o controle do público, de maneira que sejam estudados apenas os alunos que pertencem à mesma turma do primeiro ao último semestre do curso, os alunos foram recuperados pelo padrão de matrícula acadêmica. Para a aplicação do questionário, o pesquisador, com o auxílio de uma monitora, dirigiu-se aos sujeitosalvo da pesquisa. Os questionários impressos foram entregues aos alunos que se dispuseram a respondê-los ou em sala de aula ou no espaço da biblioteca do campus.

Apesar de as questões terem sido de múltipla escolha, adotou-se como forma de análise dos dados considerar apenas as duas opções escolhidas com mais frequência pelo coletivo de discentes em cada questão. Por outro lado, é necessário afirmar que, para além do roteiro generalizante que é apresentado aqui, percebe-se que o grupo de alunos pesquisados possuem roteiros próprios de pesquisa, que as seguem para lidar com os problemas informacionais, desde a definição e articular de suas necessidades de informação ao seu uso na criação de performances e produtos informacionais.

\section{RESULTADOS E DISCUSSÃO}

Tabulou-se e organizou-se os dados resultantes do questionário aplicado aos discentes do Curso Técnico em Eletrotécnica integrado ao Ensino Médio, para que se pudesse extrair e organizar inferências de acordo com os procedimentos metodológicos propostos.

\section{Categoria 1: Identificar as necessidades de informação}

O primeiro padrão de Competência em Informação afirma que o "[...] estudante competente em informação determina a natureza e a extensão da necessidade de informação" (ACRL 2000, p. 8). 
Os discentes estudados preferem "Conversar com professores e em discussões em classe, com colegas de trabalho e em discussões eletrônicas para identificar um tópico de pesquisa ou outra necessidade de informação" como melhor método para definir e articular a sua necessidade de informação (Figura 1), indicando o papel que as conversas informais possuem no esclarecimento de dúvidas no processo de pesquisa.

Figura 1. Definir e Articular a Necessidade de Informação.

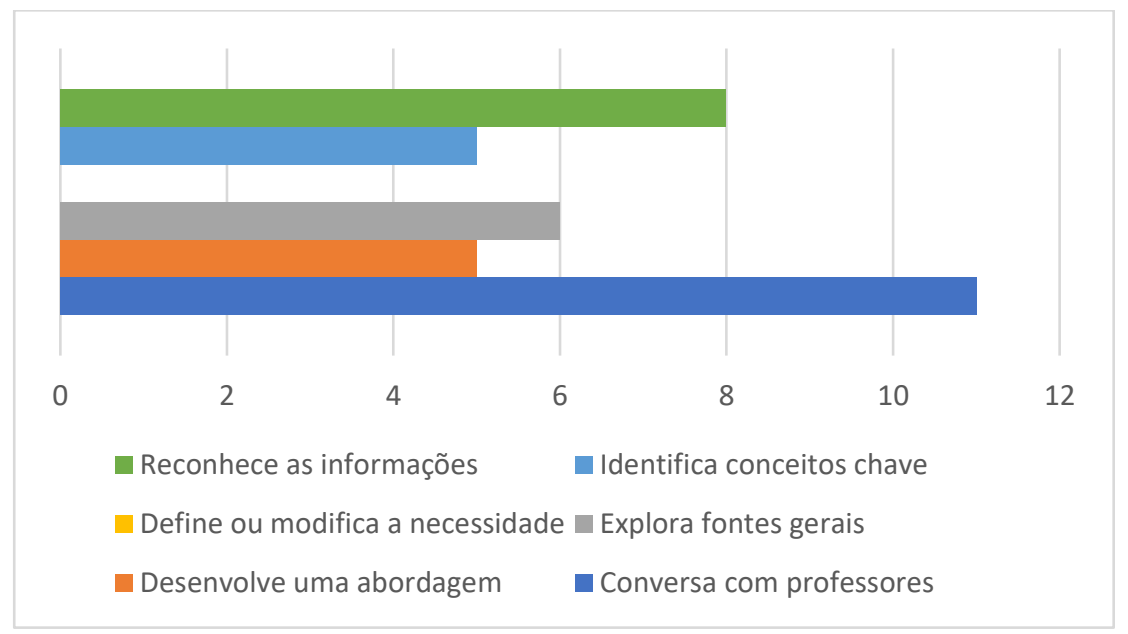

Fonte: autoria própria (2019).

Além de recorrer a conversas informais, outra ação bastante frequente entre os discentes para definir ou articular sua necessidade de informação, como explicitado no Figura 1, é "reconhecer que as informações existem como uma combinação de reflexão, experimentos e/ou análises originais para produzir novas informações", possibilitando pré-definir uma gama de possibilidades de fontes.

Os discentes, porém, evitam definir ou modificar a necessidade de informação, mantendo o foco inicial de pesquisa.

Para identificar a variedade de tipos e formatos de potenciais fontes de informação, os discentes "reconhecem que o conhecimento pode ser organizado em disciplinas, o que influencia como a informação é acessada" e "identificam o valor e as diferenças entre as potenciais fontes de informação em uma variedade de formatos" (Figura 2).

Figura 2. Identificar potenciais fontes de informação.

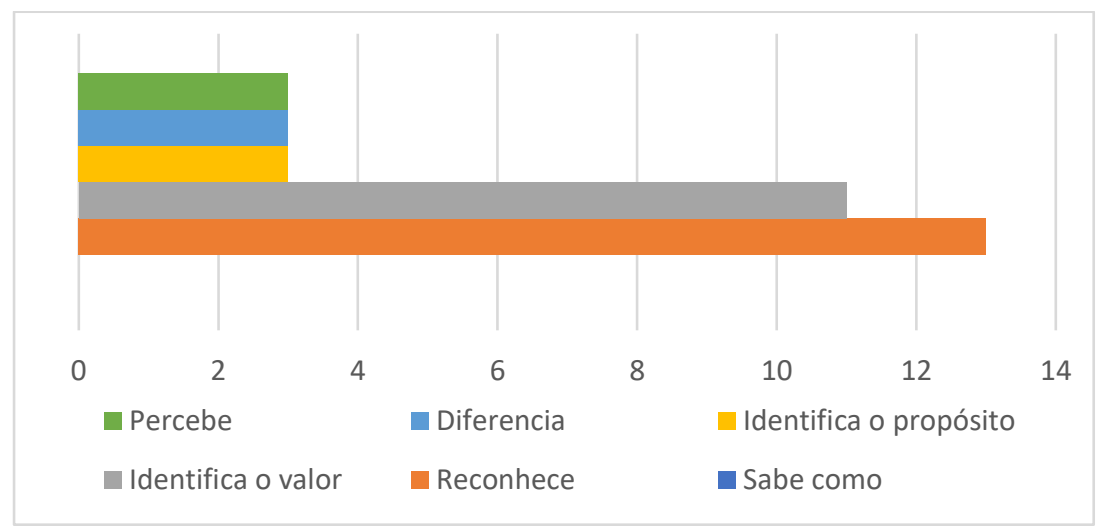

Fonte: autoria própria (2019). 
O roteiro de pesquisa nesse momento leva aos alunos a acessarem seus conhecimentos prévios sobre as fontes de informação, elencando apenas aquelas relacionadas à área do tópico que está sendo pesquisado e refletem sobre o seu valor (se é pago ou gratuito, se demanda deslocamento ou não) e se há diferenças entre uma e outra fonte de informação.

Entretanto, percebeu-se que todos os respondentes não sabem como a informação é formal ou informalmente produzida, organizada e disseminada, o que pode dificultar a sua busca pelos conteúdos nelas contidas e sobre a sua confiabilidade (Figura 2).

Em seguida, após identificar as potenciais fontes de informação, para definir custos e benefícios relacionados a essas fontes, os discentes, como na Figura 3, "determinam a disponibilidade da informação que precisam e tomam decisões sobre estender 0 processo de busca de informação a fontes locais (p. ex., empréstimo entre bibliotecas, uso de fontes em outros ambientes que os mais comuns; obtenção de imagens, vídeos, textos e sons)".

Figura 3. Custos e benefícios das potenciais fontes de informação.

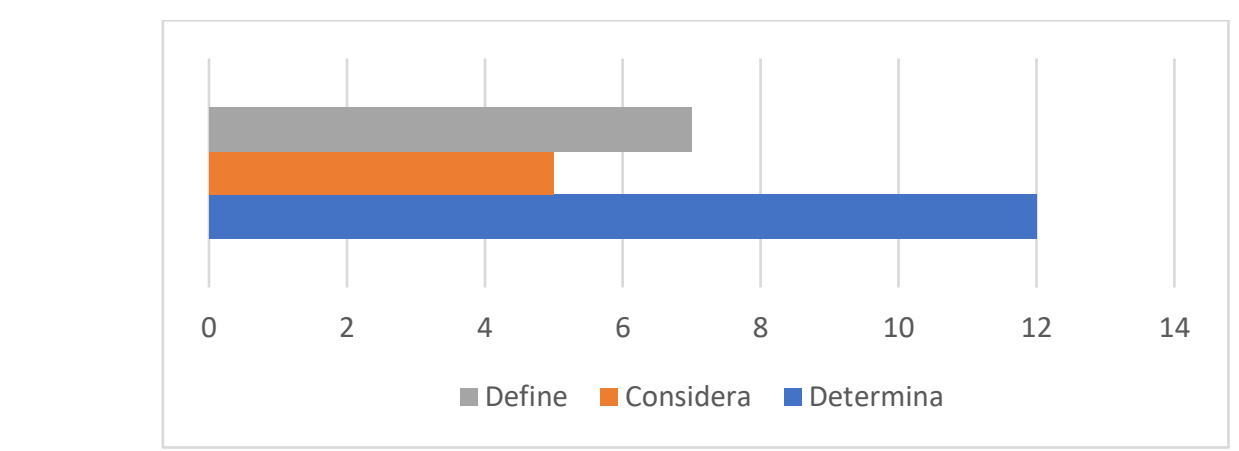

Fonte: autoria própria (2019).

Além de estender ao processo de busca de informação a fontes locais, os discentes (no Figura 3) buscam "definir um plano real global e tempo para adquirir a informação de que precisam". Nesse momento, portanto, os estudantes sabem que a informação de que precisam também pode estar em formato físico, como na biblioteca local, por exemplo, e para alcançar os resultados em tempo ágil devem estabelecer planos.

Para encerrar a categoria 1, em relação à possibilidade de reavaliar o processo de identificação da necessidade de informação, os discentes apontavam principalmente para o fato de que os alunos revisitavam a necessidade de informação inicial para clarificar, revisar ou refinar as suas questões.

Entende-se aqui, que o estudante do curso integrado para identificar sua necessidade de informação recorre a fontes informais (conversas e discussões) e formais (materiais e digitais), sabendo que elas estão distribuídas nos mais variados suportes e formatos, como resultado da diversidade de disciplinas. Diante disso, eles determinam as fontes de informação que estão interessados, estendendo a fontes locais, traçando um plano de pesquisa e revisando a necessidade de informação para dar início ao processo de busca por informação, não modificando ou redefinindo seu foco inicial. Porém se 
percebeu, por meio dos resultados, que eles não sabem como são criadas, organizadas e distribuídas as informações.

\section{Categoria 2: Acessar a informação}

O segundo padrão estabelece que, depois de identificar a necessidade de informação o indivíduo deve estar apto a acessá-la de maneira eficiente e efetiva, de acordo com a ACRL (2000).

Sobre a escolha inicial de métodos apropriados e sistemas de recuperação que auxiliem a pesquisa, a opção mais frequentemente escolhida (Figura 4) aponta que os alunos estudados preferem "selecionar abordagens eficientes e efetivas para acessar a informação de que precisam por meio de métodos de pesquisa ou sistemas de recuperação da informação", demonstrando sua necessidade de agilidade nesse processo.

Figura 4. Selecionar métodos e sistemas apropriados.

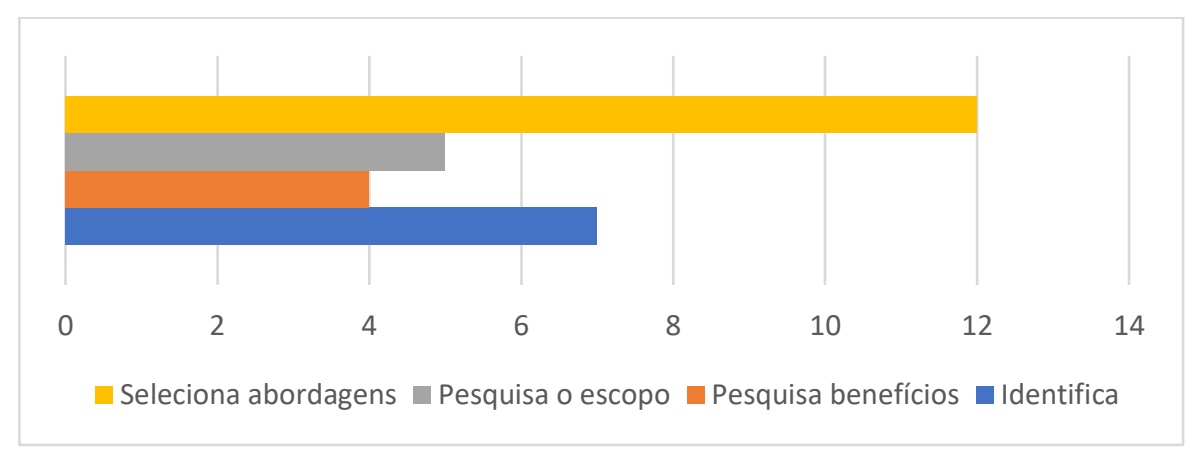

Fonte: autoria própria (2019).

Eles também preferem "pesquisar o escopo, o conteúdo e a organização dos sistemas de recuperação da informação". Desta forma, compreendendo o funcionamento dos sistemas de recuperação, as ferramentas de pesquisa e as suas qualidades previamente, os estudantes podem melhorar sua performance de pesquisa aliados às abordagens eficientes e efetivas de recuperação da informação que buscam usar.

Tendo em mãos os métodos, sistemas e abordagens de pesquisa pré-definidas, o próximo passo é construir e implementar estratégia de pesquisa eficientes e efetivas.

Figura 5. Construção e Implementação de Estratégias de Pesquisa.

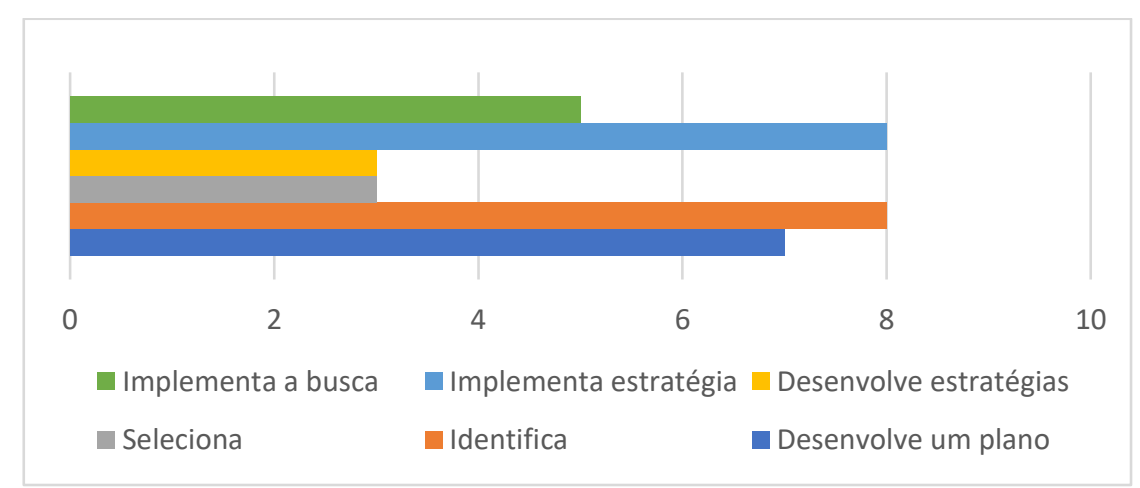

Fonte: autoria própria (2019). 
Neste caso, de acordo com a Figura 5, os estudantes "identificam palavras-chaves, sinônimos e termos relacionados à necessidade de informação" e "implementam a estratégia de busca em variados sistemas de recuperação da informação, usando interfaces e motores de busca, com diferentes comandos, protocolos e parâmetros de busca".

O foco dos alunos, nesse momento, é facilitar a busca efetiva e eficiente da informação, transformando a sua necessidade de informação em termos pesquisáveis e realizando uma busca através dos métodos e das estratégias utilizáveis nos sistemas de recuperação da informação adotados.

A desenvoltura na recuperação da informação online ou pessoalmente se dá, de acordo com os alunos (gráfico 6) por meio do "uso de serviços especializados online ou pessoalmente disponíveis na instituição em que estuda para recuperar a informação de que precisa (p. ex, empréstimo entre bibliotecas, empréstimo domiciliar, associações profissionais, departamento de pesquisa da instituição, fontes na comunidade, especialistas e profissionais)" e "utilizam vários sistemas de busca para recuperar informação em uma variedade de formatos".

Figura 6. Recuperar informação online ou pessoalmente.

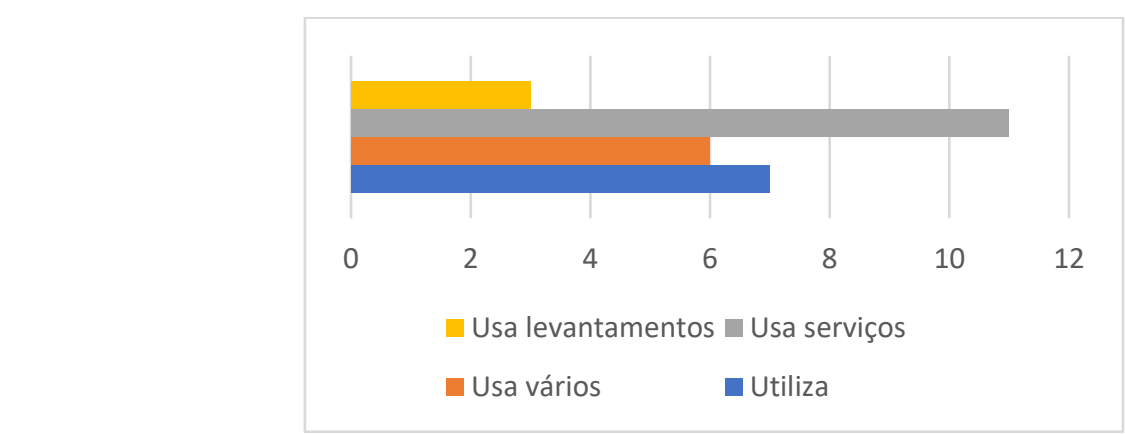

Fonte: autoria própria (2019).

O interessante de identificar nessas respostas é a importância dada pelos alunos aos serviços, sistemas e profissionais da instituição, principalmente bibliotecas e bibliotecários na efetivação e na eficiência da busca por informação para atender às suas necessidades de informação. Os dados obtidos na Figura 6 mostram também que os discentes utilizam todas as ferramentas disponíveis para recuperar informação pessoalmente ou online.

Entretanto, em caso da necessidade de refinar a estratégia de busca, os alunos "avaliam, principalmente, a quantidade, a qualidade e a relevância dos resultados de busca para determinar se um sistema de busca ou um método de pesquisa deve ser utilizado". Dessa forma, os alunos concentram-se na avaliação dos resultados recuperados, identificando suas características e se existem lacunas. Essa dedicação a uma pré-análise dos resultados aponta para uma objetividade na pesquisa e a necessidade de evitar o retrabalho.

Por fim, para extrair, registrar e gerenciar as informações das fontes de informação recuperadas, os discentes, como explicitado na Figura 7, afirmaram "selecionar entre 
as várias tecnologias a mais apropriada para realizar a extração da informação que precisa (p. ex. copiar/colar, escanear, equipamentos audiovisuais e instrumentos exploratórios".

Figura 7. Extração, Registro e Gerenciamento das informações recuperadas.

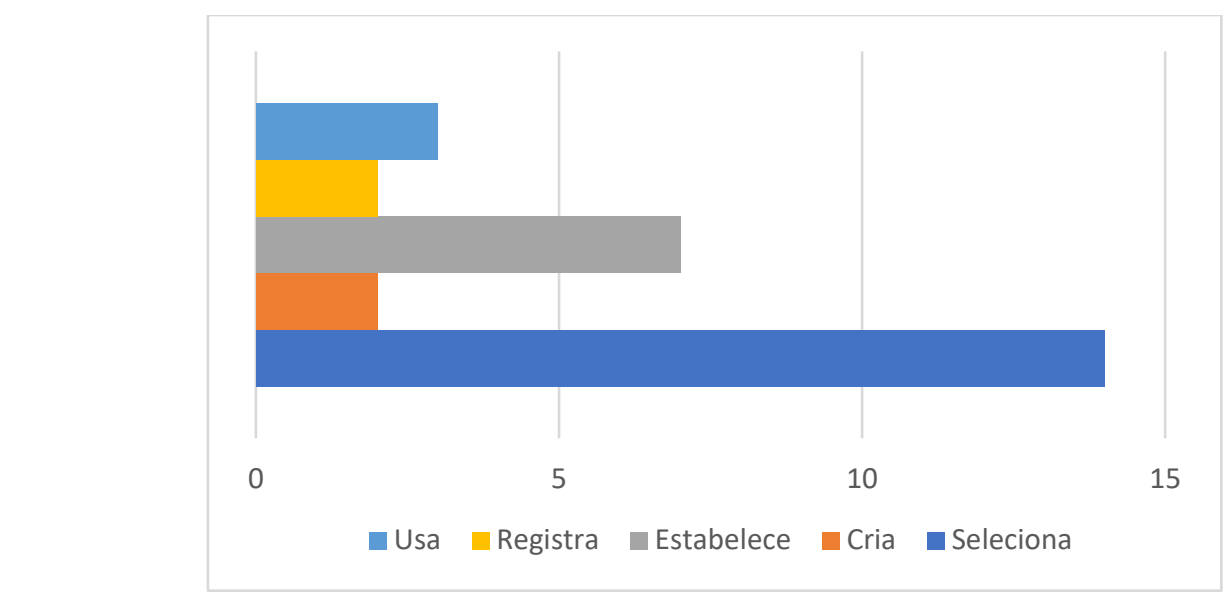

Fonte: autoria própria (2019).

Além de selecionar a tecnologia mais apropriada, os alunos costumam também "estabelecer diferenças entre os tipos de fontes de informação citadas e compreender os elementos e a correta forma de citar uma grande quantidade de fontes em um texto ou apresentação", apontando que apesar de extraírem as informações necessárias também buscam agir com ética em relação a elas, citando-as e referenciando-as adequadamente.

Os resultados observados apontam, em relação ao acesso à informação, que os estudantes selecionam abordagens eficientes e efetivas, com abordagens específicas e apropriadas. No momento da busca, identificam palavras-chave e implementam a estratégia de busca. Utilizam vários sistemas de recuperação da informação e recorrem a serviços especializados. Diante das fontes recuperadas, avaliam sua quantidade, qualidade e relevância, repetindo a busca se necessário. E por fim, selecionam várias tecnologias apropriadas para a extração da informação, estabelecendo diferenças entre as fontes e compreendendo os elementos necessários para as utilizar na citação e na referenciação.

\section{Categoria 3: Avaliar a informação}

Com a recuperação da informação necessitada, o modelo de Competência em Informação da ACRL (2000) afirma que, no Padrão 3, o estudante deve saber avaliar as informações recuperadas de maneira crítica e incorporá-la a sua base de conhecimento e sistema de valores.

Após reunir as fontes de informação e as informações recuperadas, os estudantes preferem "ler os textos e selecionar as principais ideias" para selecionar as principais ideias a serem extraídas. Como demonstrando na Figura 8, juntamente à leitura dos 
textos, outra situação recorrente entre os alunos é "reescrever o conteúdo recuperado com suas palavras e selecionar os dados com precisão".

Figura 8. Selecionar as principais ideias.

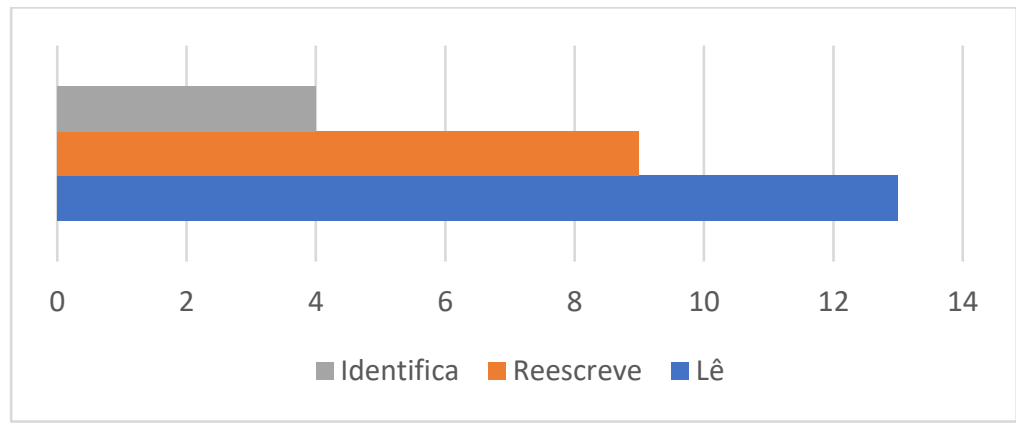

Fonte: autoria própria (2019).

Neste momento, o foco dos estudantes está em recolher apenas as informações necessárias para sua pesquisa, por meio da leitura dos materiais recuperados e a interação do usuário direto com a fonte. Eles também já extraem a informação de que precisam neste primeiro momento, selecionando os principais dados e reescrevendoos.

Para aplicar critérios de avaliação da informação, o método mais escolhido foi "examinar e comparar informações de variadas fontes de informação tendo em vista a sua confiabilidade, validade, precisão, autoridade, temporalidade e ponto de vista".

Além de examinar e comparar informações, eles preferem também, de acordo com a Figura 9, "analisar a estrutura e a lógica dos argumentos e métodos para dar suporte na sua avaliação da fonte de informação" e "reconhecer os contextos culturais, físicos, dentre outros, que cercam a criação da informação e o impacto do contexto sobre a interpretação da informação".

Figura 9. Aplicar critérios de avaliação da informação.

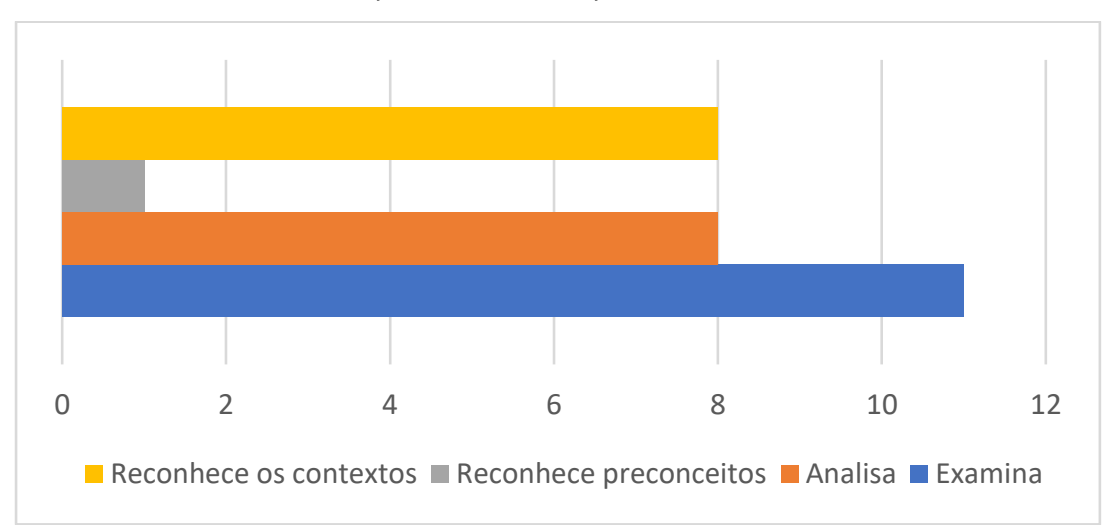

Fonte: autoria própria (2019).

Os roteiros de avaliação da informação apontam para alunos que possuem a necessidade de aplicar critérios, argumentos e métodos específicos que os permitam avaliar a informação, reconhecendo que ela é resultante de um conjunto de contextos específicos que podem afetar até mesmo a interpretação do estudante. 
Um fator negativo nos dados obtidos nesta questão é que a maior parte dos alunos não conseguem identificar ou reconhecer preconceitos, fraudes ou manipulações nas informações, o que pode influenciar na qualidade das informações que usam, estando passíveis a acessarem fontes de desinformação, informações manipuladas ou com pouca ou nenhuma credibilidade, nem avaliada por pares, por exemplo.

Avaliadas as novas informações, para sintetizar suas principais ideias e construir novos conceitos a partir delas, de acordo com a Figura abaixo, os discentes preferem "reconhecer a inter-relação entre conceitos e combiná-los para a criação de um ponto de vista passível de uso como evidência para apoiar sua proposta de trabalho" (Figura 10).

Figura 10. Sintetizar ideias e Construir novos Conceitos.

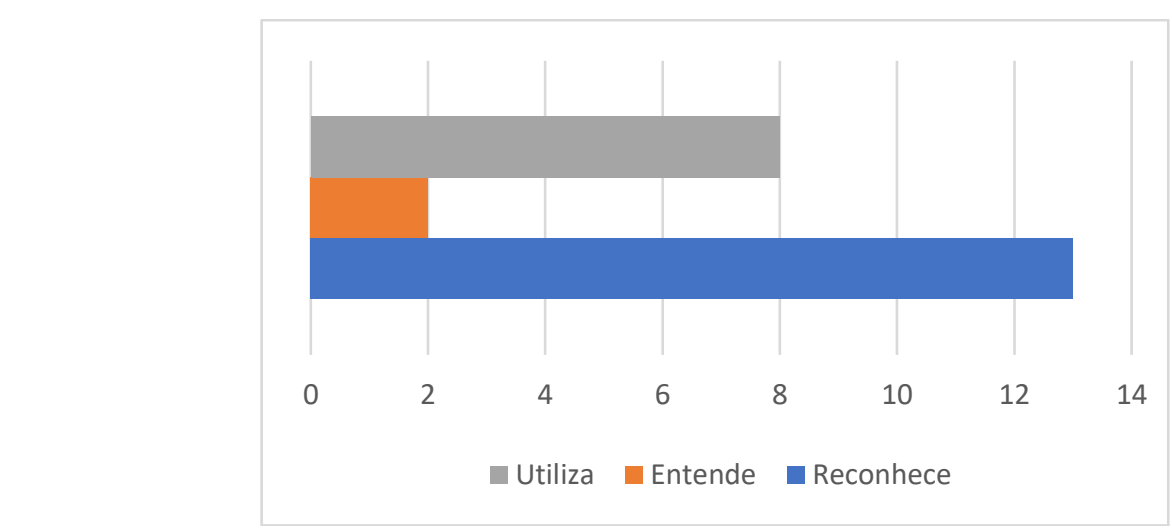

Fonte: autoria própria (2019).

Eles também "utilizam o computador e outras tecnologias (p. ex.: planilhas, bancos de dados, multimídias e equipamentos audiovisuais) para estudar a interação de ideias e outros fenômenos", ressaltando do fato de que as tecnologias da informação estão presentes no processo de acesso, avaliação e uso da informação, facilitando a comparação de informações, a separação do conteúdo por tópicos e na criação de novos conhecimentos.

Para comparar novos conhecimentos a antigos e determinar o valor adicionado, os alunos preferem "determinar se a informação que encontraram como resultante do processo de busca satisfaz a pesquisa ou outras necessidades de informação", como explicitado no Figura 11. 
Figura 11. Comparar novos a antigos conhecimentos.

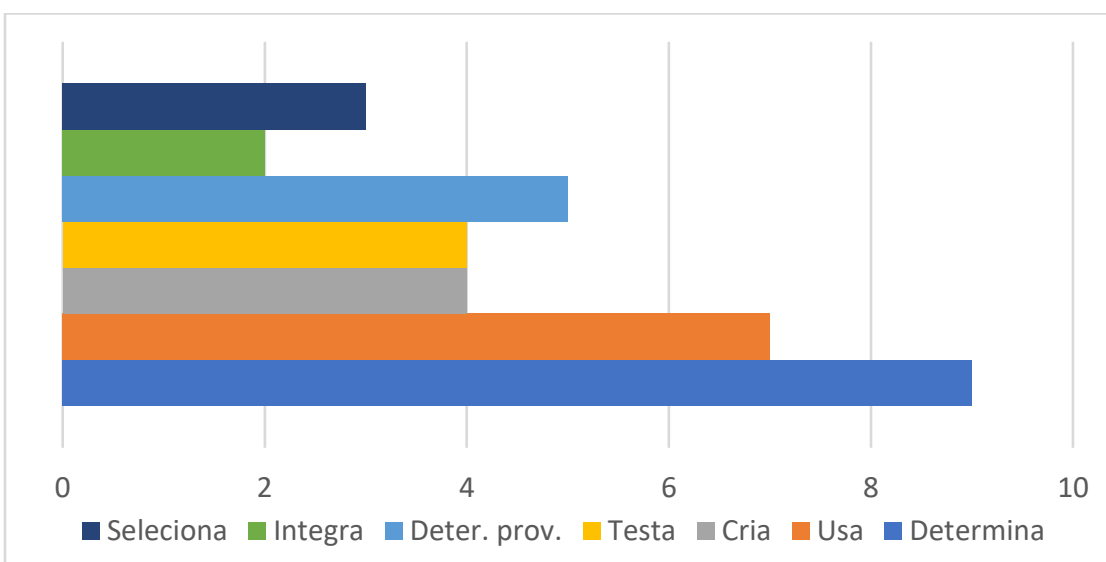

Fonte: autoria própria (2019).

E, dentre uma multiplicidade de possibilidades, eles também buscam "usar conscientemente os critérios selecionados para determinar se as informações encontradas se contradizem ou verificam se as informações são utilizadas por outras fontes de informação".

Em seguida para determinar se os novos conhecimentos causaram impacto a sua base inicial de conhecimento, mudando seu sistema de valores e propondo meios para criação ideias diferentes, eles "determinam se incorporam ou rejeitam os pontos de vista encontrados" nas fontes de informação que recuperaram.

Esses novos conhecimentos integrados à base do aluno, porém, deve passar também por validação externa, de acordo com a ACRL (2000). Para validar os conhecimentos, dessa forma, os estudantes buscam primeiro discutir suas conclusões com os seus colegas de classe (Figura 12).

Figura 12. Validar as Informações.

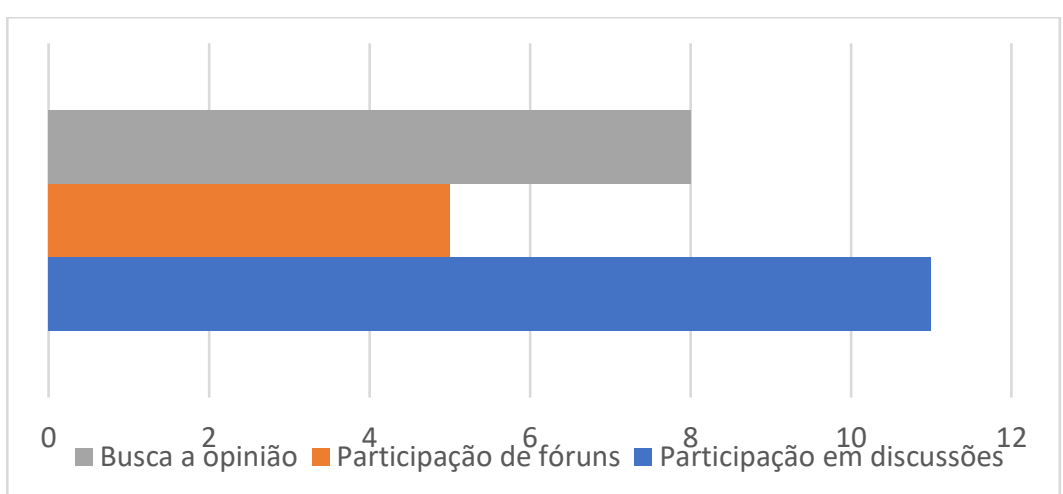

Fonte: autoria própria (2019).

Outra possibilidade também frequentemente apontada pelos alunos indica que eles "buscam opinião de especialistas por meio de uma variedade de mecanismos (ex.: entrevistas, email, listservs)", mantendo assim a possibilidade de sanar dúvidas e identificar se sua interpretação e compreensão do conhecimento adquirido estão alinhados com os próprios especialistas da área que está estudando. 
Por fim, a última categoria que encerra este padrão trata da avaliação da pesquisa como um todo. Os discentes, nesse sentido, reagem de duas maneiras principais, primeiramente "determinando se a necessidade de informação original foi satisfeita ou se informação adicional é necessária" e também "revê as fontes de recuperação da informação usadas e as expande para incluir outras se necessário".

Nesta categoria, percebeu-se que os alunos leem o material recuperado, identificando sua origem para posterior citação. Eles possuem peculiaridades individuais ante o coletivo sobre como avaliam a informação propriamente dita e comparam conhecimentos novos com antigos. Percebem também a necessidade de interrelacionar conhecimentos novos com antigos, avaliam a aquisição do conhecimento por meio da revisão da literatura, determinam se incorporam ou rejeitam o novo conhecimento, interagem com colegas e especialistas para validarem os conhecimentos novos obtidos, reveem se as fontes de informação são o suficiente para atender a sua necessidade de informação inicial ou se é necessário expandir os resultados. Porém, estão vulneráveis a informações enviesadas, manipuladas e com conteúdo preconceituoso.

\section{Categoria 4: Usar a Informação}

O quarto padrão de Competência em Informação da ACRL (2000, p. 13) trata das habilidades que o indivíduo competente em informação deve possuir para usar adequadamente a informação e suas fontes, "[... ] individualmente ou como membro de um grupo [...] para cumprir um propósito específico".

Na aplicação de novas e antigas informações para planejar e criar um produto ou uma performance em particular, os discentes preferem com maior frequência, de acordo com o Figura 13, "organizar o conteúdo em uma maneira que dê suporte aos propósitos e formatos do produto ou performance (ex. avaliações, trabalhos escritos e apresentações)".

Figura 13. Planejar e Criar um Produto ou Performance.

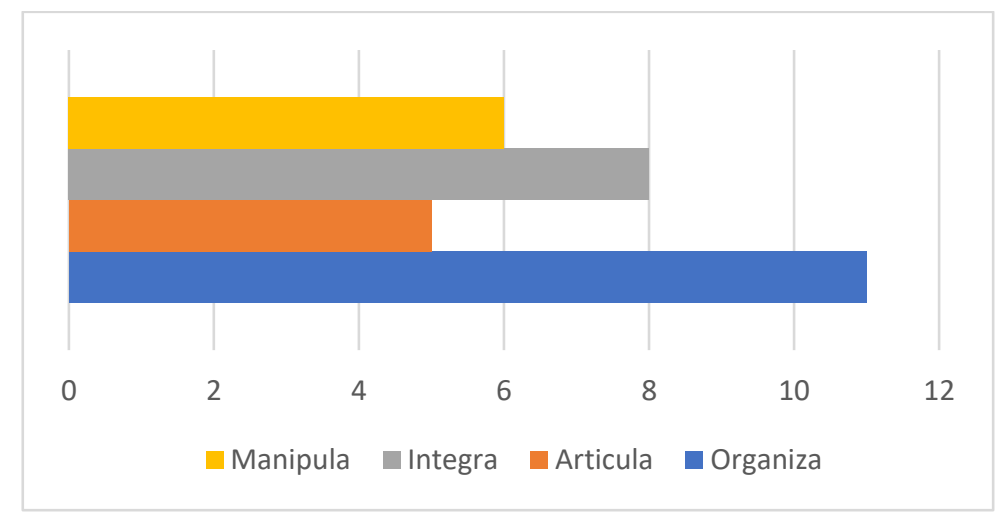

Fonte: autoria própria (2019).

Eles também "integram novas e antigas informações, incluindo citações e paráfrases de uma forma que dê suporte aos propósitos do produto ou da performance", 
revelando a importância que dão à organização das informações obtidas na criação de um novo projeto e combinam argumentações próprias com argumentações encontradas na literatura.

Para a revisão do processo de desenvolvimento do projeto, os discentes se dividiram em dois grupos: os "mantém um diário ou registro de atividades relacionados ao processo de busca, avaliação e comunicação da informação", os que escolhem "refletir sobre êxitos, falhas e alternativas passadas".

A última categoria deste padrão encerra todo o processo informacional com a apresentação dos resultados. Para apresentar o produto ou a performance efetivamente para outras pessoas, os estudantes preferem "escolher um meio ou formato de comunicação que dê melhor suporte para os propósitos do produto ou da performance e do público-alvo".

Figura 14. Apresentação dos Produtos ou Performance.

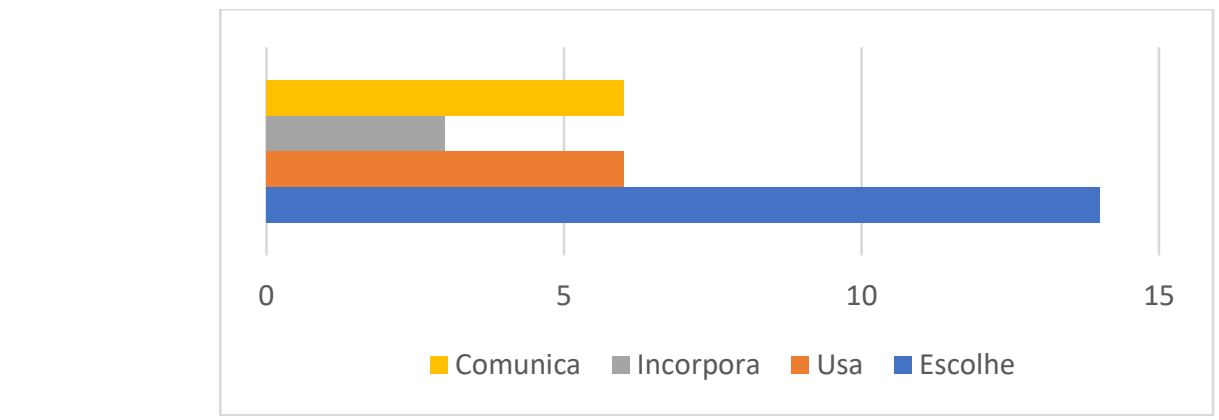

Fonte: autoria própria (2019).

Nesse caso, como é possível visualizar na Figura 14, percebe-se também que os alunos, além de escolher o meio ou formato de comunicação, preferem também "usar uma grande quantidade de tecnologias da informação para a criação de um produto e de uma performance" e "usar meios para comunicá-la claramente com um estilo que dê suporte ao propósito do público-alvo ao qual se destina".

Os resultados obtidos apontam para alunos que têm ciência que os contextos, requisitos e o público-alvo são essenciais para a construção final de um produto e performance, buscando escolher sempre os mais adequados meios, formatos, tecnologias e metodologias de apresentação.

No padrão 4, percebeu-se que os alunos estão focados em atender aos propósitos que geraram a necessidade de informação por meio das informações coletadas, organizando o conteúdo, registrando o processo criativo, definindo tecnologias e métodos que avaliem o planejamento, a construção e execução de seus projetos informacionais e utilizando meios adequados para comunicá-las ao seu público-alvo. 


\section{Categoria 5: Compreender as questões que cercam o acesso e uso da informação}

O último padrão do modelo de Competência em Informação da ACRL (2000) trata das questões éticas, econômicas, sociais, culturais e políticas que cercam o acesso e o uso da informação.

Em relação ao conhecimento dos alunos sobre questões legais, éticas e socioeconômicas que cercam o uso da informação e de suas tecnologias, os estudantes, de acordo com a Figura 15, buscam "identificar e discutir questões relacionadas à privacidade e à segurança tanto em ambientes impressos como em ambientes eletrônicos".

Figura 15. Questões éticas, legais e socioeconômicas da informação

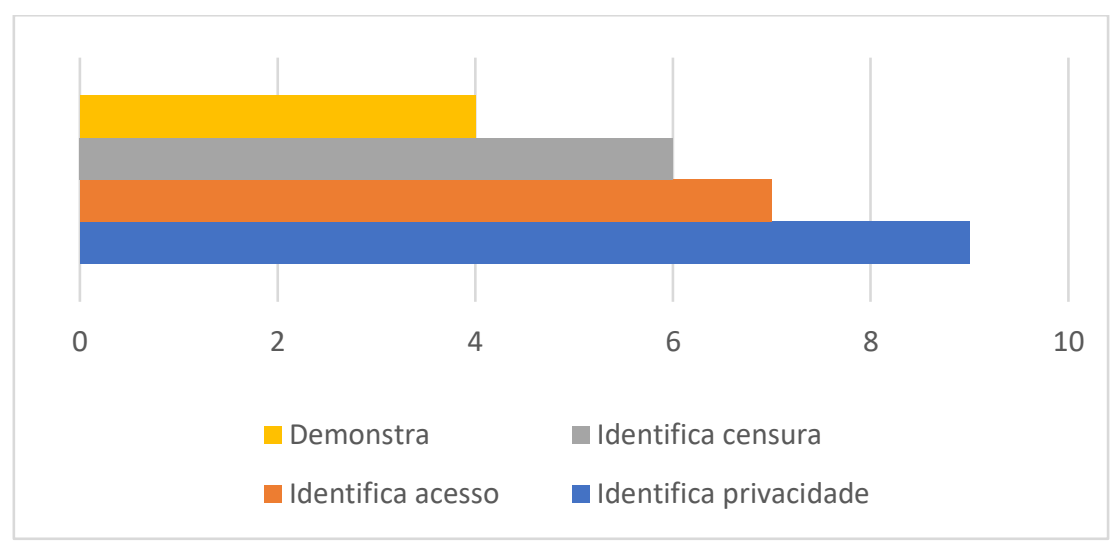

Fonte: autoria própria (2019).

Além disso, percebeu-se o fato de que além de segurança e privacidade, os alunos "identificam ou discutem questões relacionadas à censura e a liberdade de expressão". Ambas as respostas reafirmam que os alunos estão preocupados quanto ao acesso e uso da informação, mas, que também precisam saber que sua segurança informacional e sua privacidade estão sendo asseguradas, assim como se está sendo assegurado o acesso a todo o conteúdo disponível que lhes diz respeito, sem censura, bem como, ter liberdade para se expressar.

Quanto ao questionamento sobre a necessidade de se seguir leis, regulamentos, políticas institucionais e éticas relacionadas ao acesso e uso da informação, os estudantes "demonstram, principalmente, uma compreensão sobre o que é o plágio e não usam como seus trabalhos atribuídos a outras pessoas". 
Figura 16. Seguir leis e regulamentos sobre o acesso e uso de informação.

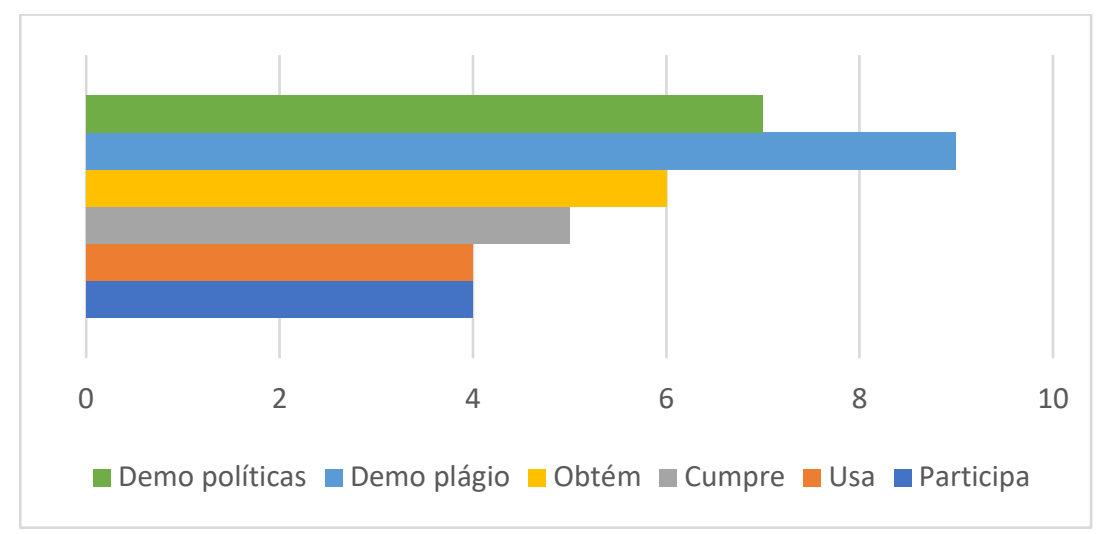

Fonte: autoria própria (2019).

Neste caso, existe, como é possível ver na Figura 16, um certo equilíbrio sobre as leis e legislações relacionadas ao acesso e uso da informação. Os dados apontam também para a busca de uma postura ética no acesso e uso da informação e de fontes de informação pelos alunos, buscando estar atentos às suas permissões e aos problemas sociais, legais e éticos que cercam o acesso a conteúdo privado.

Na última categoria do padrão 5 e do modelo de Competência em Informação da ACRL (2000), os estudantes respondem que, em relação à referenciação das obras utilizadas na criação de produtos e performances, eles reconhecem que as informações recuperadas pertencem a outrem e "selecionam um padrão de escrita e a usa para citar as fontes de informação".

Globalmente, os alunos estudados, desta forma, são conscientes sobre as questões legais, sociais, econômicas e éticas que cercam o acesso e o uso da informação, preferindo seguir leis e regulamentações e políticas de acesso, questionando sempre tópicos como liberdade de expressão e censura, referenciando as obras que embasaram o seu trabalho final e selecionando um padrão de escrita para citar as fontes de informação utilizadas.

\section{Categoria 6: Informação, Trabalho e Educação}

Como agregador ao modelo, adicionou-se questões relacionadas à relação entre informação, trabalho e educação, visando estabelecer uma relação entre a Educação Profissional e a Competência em Informação dos alunos.

Sobre a possibilidade de a informação e as tecnologias da informação terem trazido mudanças substanciais na Educação, no Trabalho e na Vida Cotidiana, percebeu-se que a maioria dos respondentes esteve de acordo ou totalmente de acordo com a afirmação, estando apenas quatro indecisos. Por outro lado, em relação à possibilidade de que a Competência em Informação seja essencial para a sua formação como futuro trabalhador, todos os alunos demonstraram estar de acordo. 
Os alunos evidenciam, dessa forma, compreender que o crescimento e a evolução das novas tecnologias produziram efeitos nas dinâmicas educacionais, de trabalho e cotidianas e que para atuarem no mundo do trabalho é importante que saibam identificar suas necessidades de informação, acessar, avaliar, usar e compreender as questões que cercam a informação.

\section{CONSIDERAÇÕES FINAIS}

Tratar sobre Competência em Informação no contexto da Educação Profissional e Tecnológica brasileira ainda é um caminho pouco explorado e que demanda mais atenção e o desenvolvimento de metodologias próprias, específicas e teoricamente fundamentadas, principalmente quando se toca na questão da avaliação da informação.

A maioria dos instrumentos de monitoramento e de avaliação da informação são estrangeiros são voltados para os contextos da Educação Básica (Fundamental e Médio no Brasil) e da Educação Superior e são provenientes do eixo América do NorteEuropa-Austrália-Nova Zelândia, refletindo as experiências e as dinâmicas informacionais dos estudantes desses países e regiões e não conseguindo abarcar, apesar de adaptáveis, as vivências de estudantes latinoamericanos, brasileiros, nordestinos, do interior do Ceará.

Além dos dois fatores anteriores, grande parte desses instrumentos, principalmente os Padrões de Competência em Informação no Ensino Superior da ACRL (2000), já foram substituídos sob uma nova perspectiva, apontando para o avanço das ações de educação para a informação nas regiões em que foi criada e na mudança na proposta do conceito próprio de Competência em Informação.

Neste trabalho, apesar das mudanças relacionadas ao modelo, decidiu-se seguir as propostas da Matriz Conceitual de Oliveira e Silva (2018) e utilizar os Padrões de Competência em Informação da ACRL (2000), como oportunidade de visualizar como os concludentes de um curso técnico integrado ao Ensino Médio lidavam o processo de identificação das necessidades de informação, acesso, avaliação e uso da informação, e da indagação sobre as questões que cercam o acesso e o uso da informação.

Identificou-se ao longo da pesquisa que os alunos apresentam habilidades informacionais bem desenvolvidas, levando em consideração os Padrões de Competência em Informação da ACRL (2000).

Eles buscam utilizar métodos que facilitem o processo de busca por informação, recorrem a colegas de classe, professores e profissionais para o auxiliarem na definição de tópicos de pesquisa, avaliam a informação de maneira crítica, apesar de demonstrarem estar vulneráveis a informações enviesadas, manipuladas e preconceituosas, adicionam os novos conhecimentos a sua base inicial, utilizam as novas tecnologias para o planejamento, criação e apresentação de seus trabalhos e 
mostram-se conscientes sobre questões éticas, econômicas e políticas que cercam o acesso e uso da informação, sabendo citar, por exemplo, as fontes de informação usadas.

Respondendo, dessa forma, ao objetivo "avaliar a competência em informação dos discentes de um Curso Técnico Integrado ao Ensino Médio", conclui-se que os alunos possuem habilidades informacionais desenvolvidas, porém necessitam de uma formação informacional adequada que os leve a compreender como funciona o processo de produção da informação e a identificar informações enviesadas.

Entretanto aponta-se para a necessidade de que os estudos em Competência em Informação na Educação Profissional e Tecnológica continuem sendo desenvolvidos de maneira a que possam se criar instrumentos específicos, que atendam às próprias demandas da Educação Profissional e Tecnológica enquanto campo do conhecimento devidamente estabelecido, e que seja adaptável às dinâmicas informacionais dos jovens brasileiros em processo de profissionalização e de formação para o mundo do trabalho.

\section{REFERÊNCIAS}

AASL (American Association of School Librarians), 2009. Standards for the 21stCentury in Action. Chicago, IL: AASL.

AASL (American Association of School Librarians), AECT (Association for Education Communications and Technology), 1998. Information power: building partnerships for learning. Chicago; London: ALA.

ACRL (Association of College and Research Libraries), 2000. Information Literacy Competence Standards for Higher Education [em linha]. Illinois: ALA. [Acesso em 13 dezembro 2020]. Disponível em: https://alair.ala.org/bitstream/handle/11213/7668/ACRL\%20Information\%20Liter acy $\% 20$ Competency $\% 20$ Standards $\% 20$ for $\% 20$ Higher $\% 20$ Education.pdf?sequence =1\&isAllowed=y.

ACRL (Association of College and Research Libraries), 2016. Framework for Information Literacy for Higher Education [em linha]. [Acesso em 22 março 2021]. Disponível em: http://www.ala.org/acrl/standards/ilframework.

ANZIL (Australian and New Zealand Institut For Information Literacy); (CAUL) Council of Autralian University Librarians), 2004. Australian and New Zealand information literacy framework: principles, standards and practice. Adelaide: ANZIL. [Acesso em 22 março 2021]. Disponível em: http://archive.caul.edu.au/info-literacy/InfoLiteracyFramework.pdf.

BELLUZZO, Regina Célia Batista; KERBAUY, Maria Teresa Miceli, 2004. Em busca de parâmetros de avaliação da formação contínua de professores do 
ensino fundamental para o desenvolvimento da information literacy. ETD Educação Temática Digital [em linha]. 2004. v. 5, n. 2, p. 129-139, 2004. [Acesso em 22 março 2021]. Disponível em:

https://periodicos.sbu.unicamp.br/ojs/index.php/etd/article/view/766.

BRASIL, 2007. Educação Profissional Técnica de Nível Médio Integrada ao Ensino Médio: documento base. Brasília, DF: SETEC, MEC. [Acesso em 13 dezembro 2020]. Disponível em: http://portal.mec.gov.br/setec/arquivos/pdf/documento_base.pdf.

DUDZIAK, Adriana Elisabeth, 2003. Information Literacy: princípios, filosofia e prática. Ciência da Informação [em linha]. 2003. v. 32, n. 1, p. 23-35. [Acesso em 13 dezembro 2020]. Disponível em: http://revista.ibict.br/ciinf/article/view/1016/1071.

OLIVEIRA, Andreia Silva de e SILVA, Carlos Robson Souza da Silva, 2018. Competência em Informação na Educação Profissional: um relato de experiência. Em: Seminário de Iniciação Científica do IFCE, campus Cedro [em linha]. Cedro, CE: DEPPI, IFCE. 2018.[Acesso em 13 dezembro 2020]. Disponível em: https://ifce.edu.br/cedro/arquivos/copy_of_AnaisSEMIC2019.pdf.

SANTOS, Camila Araújo dos, 2017. Competência em Informação na formação básica dos estudantes da educação profissional e tecnológica [em linha]. Tese (Doutorado em Ciência da Informação). Marília, SP: Universidade Estadual Paulista. [Acesso em 13 dezembro 2020]. Disponível em:

https://www.marilia.unesp.br/Home/PosGraduacao/Cienciadalnformacao/Dissertacoes/santos_ca_do.pdf.

SANTOS, Camila Araújo; CASARIN, Helen Castro Silva, 2014. Habilidades informacionais abordadas em instrumentos de avaliação de $\mathrm{Cl}$. Informação \& Sociedade: Estudos [em linha]. 2014. v. 24, n. 3, p. 135-144. [Acesso em 22 março 2019]. Disponível em: http://www.brapci.inf.br/index.php/res/v/92010.

SAVIANI, Dermeval, 2007. Trabalho e Educação: fundamentos ontológicos e históricos. Revista Brasileira de Educação [em linha]. 2007. v. 12, n. 34, p. 152165. [Acesso em 13 dezembro 2020]. Disponível em: http://www.scielo.br/pdf/rbedu/v12n34/a12v1234.pdf.

SCONUL (Society of College, National and Universtiy Libraries), 2011. The SCONUL Seven Pillars of Information Literacy: core model for higher education. [London]: SCONUL. [Acesso em 22 março 2021]. Disponível em: https://www.sconul.ac.uk/sites/default/files/documents/coremodel.pdf. 